\title{
Case Study on the Stability Control of Broken Surrounding Rock in Roadway Excavation on the Edge of a Collapsed Stope Area
}

\author{
Yabin Wu, ${ }^{1,2}$ Jianhua Hu, ${ }^{1}$ Chengyu Xie $\mathbb{D}^{3}$ and Dongping Shi ${ }^{3}$ \\ ${ }^{1}$ School of Resources and Safety Engineering, Central South University, Changsha 410083, China \\ ${ }^{2}$ Changsha Institute of Mining Research Co., Ltd., Changsha 410012, China \\ ${ }^{3}$ School of Environment and Resources, Xiang Tan University, Xiangtan 411105, China \\ Correspondence should be addressed to Chengyu Xie; xiechengyu42@xtu.edu.cn
}

Received 1 July 2021; Accepted 30 August 2021; Published 13 September 2021

Academic Editor: Jie Liu

Copyright $\odot 2021$ Yabin Wu et al. This is an open access article distributed under the Creative Commons Attribution License, which permits unrestricted use, distribution, and reproduction in any medium, provided the original work is properly cited.

Predicting and controlling the collapse of surrounding rock (especially broken rock masses) in underground chambers is an important topic in mining and geotechnical engineering. Based on an example, this paper introduces a case study of surrounding rock stability control technology in stope mining around abandoned areas. Based on on-site coring, mechanical properties of rock samples, and on-site grouting reinforcement technology, the TRT6000 advanced geological prediction system was used to predict the stability status of the surrounding rock of the underground chamber. AUTODYNA software was used to build a dynamic coupling model for numerical simulation prediction and optimization of blasting parameters and to reveal the dynamic variation in the surrounding rock. The dynamic failure process of the surrounding rock of the chamber before and after optimization of the blasting parameters is simulated, and the deformation characteristics and damage and acoustic emission characteristics of the surrounding rock are clearly shown. The surrounding rock failure first appeared around the surface of the underground chamber because of the high stress concentration around the surface of the chamber after blasting; with the interaction between the explosive gas and the rock mass, the damaged area further propagated into the external rock, eventually leading to a large damage area. At the same time, there is a large tensile failure in the rock, resulting in expansion and rupture around the underground chamber. Finally, the 3D laser scanning method is used to verify the superiority of the optimized blasting initiation sequence. The new edge hole detonation sequence can effectively improve the blasting vibration and successfully control the further damage of the surrounding rock of the underground chamber, thus proving the edge hole drug pack. Moreover, the initiation mode of the delay stage of the side hole charge is determined. This study provides a useful reference for the stability control of surrounding rock in mining in mining areas.

\section{Introduction}

Shallow mineral resources are becoming exhausted, and mining at a depth of 10-25 meters has increased; however, the ore bodies at such depths are still marginal, complex or difficult to recover before mining, unexplored, high grade, and difficult to exploit ore bodies. For these resources, the failure mechanism of the surrounding rock of the underground chamber is obviously different from that of the shallow intact rock mass. For example, the surrounding rock mass is uneven, and there are many holes and cracks [1]. It is more prone to a series of engineering problems with large deformations, and associated projects do not appear. Certainty can seriously affect mining production and safety, thus leading to instability in roadways or underground chambers [2]. Therefore, in the complex mining environment, the stability control problem of the roadway or underground chamber during mining marginal hard-to-mine bodies has received extensive attention [3].

There are two difficulties in the stability control of roadways or ditches during mining marginal hard-to-mine bodies [4]. The failure mechanism of surrounding rock under complex ground stress is still unclear, and existing field detection methods are difficult to predict effectively and accurately. 
The main methods for studying the failure mechanism of roadways or chamber surrounding rock in complex environments include field tests [5-7], model tests [8, 9], theoretical analytical calculations $[10,11]$, and numerical simulations. In recent years, scholars have developed and adopted various numerical simulations to analyze the instability mechanism of roadways or underground chambers. Compared with other research methods, numerical methods have the advantages of low cost, high efficiency, and good repeatability. Many successful cases using numerical methods have shown the feasibility of using numerical methods to simulate the failure mechanism of roadways or surrounding rocks and show a mechanical model of roadway surrounding rock. The different forces of the plastic zone of the roadway were studied by field observation, theoretical analysis, numerical simulation, and field test. Combining the finite element limit analysis of SDP and LB, the program was successfully developed and used to study the stability of unlined square tunnels in Hoek-Brown (HB) materials [12]. The two-dimensional finite element simulation method was used to study the redistribution of ground stress and dynamic damage of rock caused by blast loading [13], and it applied the FEM-DEM method to reproduce the dynamic process of rock fragment blasting [14]. The interaction between gas and blastholes was studied using the DEM-SPH method [15]. The finite element method (FEM) and discrete element method (DEM) were used to characterize the stress evolution caused by mining [16]. The above research provides a reference for the mechanism of the stability of the surrounding rock in the special environment [17], although for a specific mine, and because of its complex geological conditions, the lithology of the rock mass is different; therefore, under complex environmental conditions, the failure mechanism of the surrounding rock of the roadway or the underground chamber remains to be revealed [18], especially for the process analysis of the instability of the surrounding rock [19].

At present, the problem of stability control of surrounding rock in stope mining within the scope of degraded stopes is still a hot and challenging issue [20]. The above research results laid the foundation for further research on surrounding rock control technology in stope mining within the range of mining and mining. Many practices have proven that it is difficult to achieve the problem of surrounding rock deformation control under complex mining conditions by a single method. The specific engineering problems show that the combination of comprehensive methods is an effective method of solving the stability problems of such underground chambers or tunnels. To solve such problems, this paper combines specific mines to study a case of surrounding rock control technology in ore mining within the scope of degraded stopes. By using field data and laboratory results, TRT6000 equipment was used to detect the roadway before mining. Then, the numerical simulation is carried out with AUTODYNA software. The evolution process of surrounding rock deformation in the goaf is studied. A new blasting initiation sequence is proposed to reduce the blasting vibration, control the surrounding rock damage, and carry out the detection of the field goaf. The control effect of the new blasting scheme on the stability of the surrounding rock in the goaf is then evaluated.

\section{Case Study}

To study the stability of broken surrounding rock in stope mining in the collapsed area, the site must first be studied.

2.1. Current Situation in the Collapsed Stope Area. The instability and collapse area of a metal lead-zinc mine (exploited by the filling method) is shown in Figure 1 (model length $68 \mathrm{~m}$, width $40 \mathrm{~m}$, and height $64 \mathrm{~m}$ ). Because of the goaf formation, the filling body and upper ore body appeared, causing a massive collapse. The mining stope in the picture belongs to the marginal ore body in the unstable collapse area. The mining sequence is determined to be bottom-up mining. The lowermost part of the $22 \mathrm{~m}$ high ore body still uses bottomless deep hole back-return mining and postfilling mining. When the method is used for mining, mining is carried out at a height of approximately $8 \mathrm{~m}$ (first, the area circled in red in Figure 1), and mining uses a trolley to punch up the charge and blast it at a time. The method forms a small goaf but has a large blasting vibration; therefore, further decreases in the blasting vibration are possible. The blasting vibration should be reduced as much as possible.

2.2. Grouting Reinforcement Analysis. According to the practice of the lead-zinc mine, the cement-based slurry grouting method is first used to fill and grout the collapsed area to improve the stability of the surrounding rock. Since there was no engineering practice experience in the collapsed area before the mine, similar mines did not find relevant treatment methods. The No. 1 stope was used to arrange the grouting holes (shown in Figure 2) to fill and compact the No. 2 stope and No. 3 cavities and cracks in the stope.

Through the backwater recording of core drilling, on-site footage, and detection of the strength of the core sample, the overall strength of the filling is known [21]. The rock samples were classified and numbered according to the design and properly sealed. The rock samples of the ore body and the filling body were selected for rock mechanics experiments. For the cracks that may occur in the ore body discovered during the sampling survey, the sliding surface is pressurefilled, and the cavities and cracks found in the filling body are pressure-filled.

The three-dimensional visualization pattern of the grouting hole is determined by the plan view of the drilling arrangement form for grouting the collapsed area. The detailed parameters of each grouting hole are shown in Table 1. The design principle of the grouting hole is as follows: the center position of the collapsed area should be drilled during drilling, especially the No. 2 stope to be mined, and the surrounding rock on the north side is in the edge position of the collapsed area; therefore, the grouting should be strengthened in this area, and the stability of the two-pack filling should be improved. 


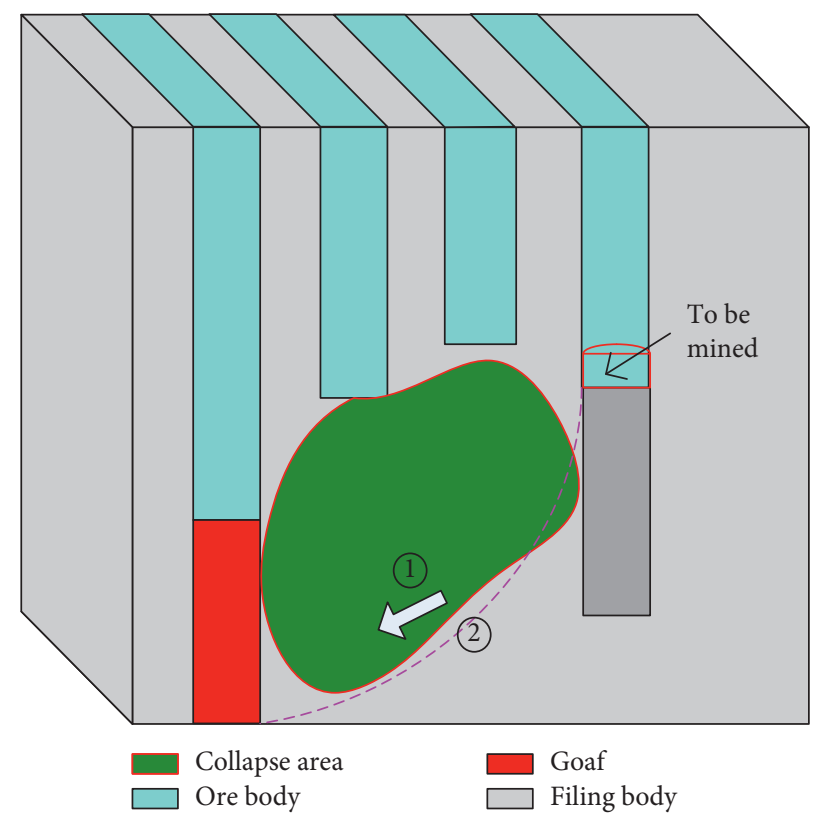

FIgURE 1: Mining status of the instability collapse area.

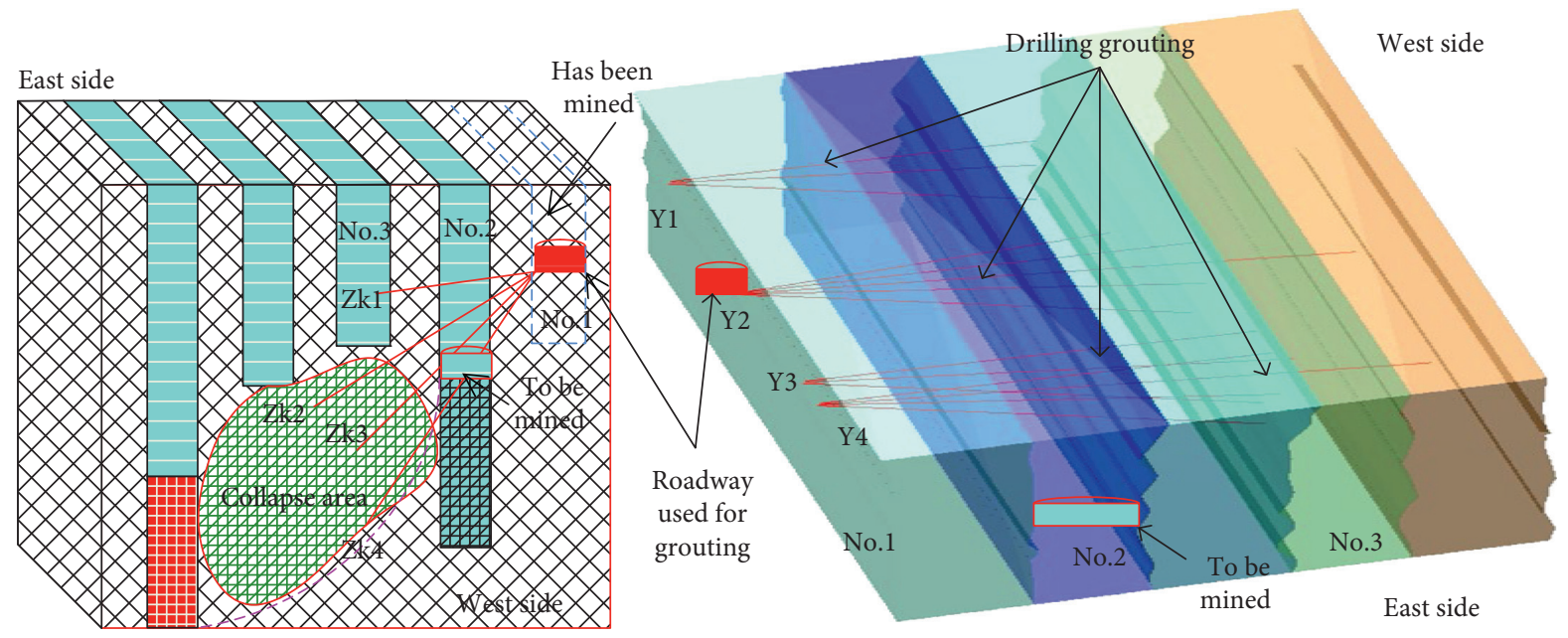

FIGURE 2: Grouting reinforcement diagram.

\subsection{Rock Sample Analysis}

2.3.1. On-Site Coring Analysis. The occurrence of ore bodies and backfills in the collapsed area varies greatly, and even the lithology of the backfill in the same stope varies greatly. It is especially important to perform core analyses on the ore body and the filling body in the collapsed area. The drilling core can more accurately identify voids and cracks in the filling body (Figure 3). Based on the geological cataloging of the drilled core, the stability of the surrounding rock is determined by analyzing the integrity of the core during drilling by the RQD value. To detect and judge the effect of grouting in the ore body, the RQD value is calculated before and after grouting. The statistical results are shown in $\mathrm{Ta}-$ bles 2 and 3.
Tables 2 and 3 show that the integrity of the ore body has changed significantly before and after grouting, and the integrity of the rock mass has been significantly improved. The original integrity is poorly improved to a medium-intact, medium-complete ore body. Increase to the mineral rock body is more complete. This finding shows that grouting has a good effect on improving the integrity of the ore body.

2.3.2. Analysis of the Mechanical Properties of the Rock Mass before and after Grouting Reinforcement. To compare the lithological changes before and after grouting, the core after grouting was preserved and rock mechanics experiments were carried out [22]. 
TABLE 1: Summary of grouting drilling arrangement parameters.

\begin{tabular}{|c|c|c|c|c|}
\hline Numbering & Orifice position $(\mathrm{m})$ & Hole number & Drilling angle $\left({ }^{\circ}\right)$ & Drill length $(\mathrm{m})$ \\
\hline \multirow{3}{*}{1} & \multirow{3}{*}{$\begin{array}{c}Y 1 \\
H=-240\end{array}$} & ZK1 & -6.0 & 21.0 \\
\hline & & $\mathrm{ZK} 2$ & -31.0 & 25.0 \\
\hline & & ZK3 & -53.0 & 35.0 \\
\hline \multirow{4}{*}{2} & \multirow{4}{*}{$\begin{array}{c}Y 2 \\
H=-240\end{array}$} & $\mathrm{ZK} 1$ & -6.0 & 26.0 \\
\hline & & $\mathrm{ZK} 2$ & -24.0 & 35.0 \\
\hline & & ZK3 & -39.0 & 34.0 \\
\hline & & ZK4 & -53.0 & 43.0 \\
\hline \multirow{3}{*}{3} & \multirow{3}{*}{$\begin{array}{c}Y 3 \\
H=-240\end{array}$} & $\mathrm{ZK} 1$ & 20.0 & 26.0 \\
\hline & & $\mathrm{ZK} 2$ & 0.0 & 34.0 \\
\hline & & ZK3 & -16.0 & 43.0 \\
\hline \multirow{4}{*}{4} & \multirow{4}{*}{$\begin{array}{c}Y 4 \\
H=-40\end{array}$} & ZK1 & 28.0 & 25.0 \\
\hline & & $\mathrm{ZK} 2$ & 0.0 & 35.0 \\
\hline & & ZK3 & -29.0 & 34.0 \\
\hline & & ZK4 & -64.0 & 43 \\
\hline
\end{tabular}

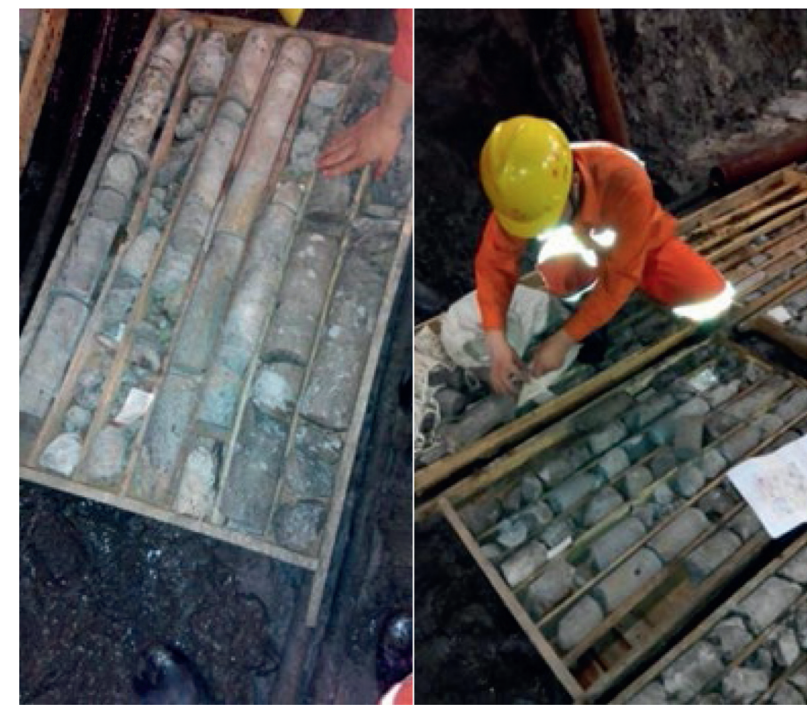

Figure 3: Drilling the core at the site.

By comparing the changes in the mechanical properties of the core and the filling body (mainly the change in shear strength), the effect of grouting reinforcement of the ore body and the filling body can be indirectly reflected to some extent. The uniaxial shear strength of the ore and the backfill after grinding grouting is greatly improved. Here, the grouting reinforcement coefficient $\alpha$ is defined as the ratio of the uniaxial shear strength before and after grouting reinforcement. According to the statistics of the uniaxial shear strength before and after grouting reinforcement (Figures 4 and 5), the average shear strength of the ore after grouting reinforcement is $66.2 \mathrm{MPa}$, the average reinforcement coefficient is 2.51 , the average shear strength of the backfill is $3.64 \mathrm{MPa}$ and $2.42 \mathrm{MPa}$, and the average reinforcement factor is 1.26 and 1.15. Therefore, comparing the absolute value increment of the uniaxial shear strength with the grouting reinforcement coefficient, it is shown that higher looseness of the grouted and strengthened rock mass corresponds to worse internal structuralism. This finding shows that grouting reinforcement has produced an effect. The uniaxial shear strength test before and after grouting reinforcement can be obtained. The deformation resistance of the ore body and the backfill after grouting is significantly improved, showing that the rock mass and the backing body resist shear after grouting reinforcement. The deformation capacity is increased.

Compared with the nongrouting reinforcement, the shear strength parameters of the rock mass and the filling body are obviously improved. The cohesive force and internal friction angle of the rock mass are increased by $101.0 \%$ and $7.4 \%$, respectively, and the cohesive force of the filling body and the internal friction angle are increased by $52.2 \%$ and $2.4 \%$, respectively. With grouting reinforcement, the mechanical properties of the rock and the filling body are improved, and the cohesion is mainly improved.

2.4. Field Detection Analysis. Excavation roadway detection: when digging into the underground chamber, there may be broken areas in the surrounding rock, and the roadway is 
TABLE 2: Statistical results of the RQD values before grouting.

\begin{tabular}{lccccc}
\hline Drill number & Hole depth $(\mathrm{m})$ & Inclination $\left(^{\circ}\right)$ & Elevation $(\mathrm{m})$ & Coordinate line & RQD value $(\%)$ \\
\hline ZK1 & 26.0 & -6 & -240.0 & $Y 2$ & 43.15 \\
ZK2 & 35.0 & -24 & -240.0 & $Y 2$ & 52.72 \\
ZK3 & 34.0 & -39 & -240.0 & $Y 2$ & 48.68 \\
ZK4 & 43.0 & -53 & -240.0 & $Y 2$ & 54.36 \\
\hline
\end{tabular}

TABLE 3: Statistical results of the RQD values after grouting.

\begin{tabular}{lccccc}
\hline Drill number & Hole depth $(\mathrm{m})$ & Inclination $\left(^{\circ}\right)$ & Elevation $(\mathrm{m})$ & Coordinate line & RQD value $(\%)$ \\
\hline ZK1 & 25.0 & 28 & -240.0 & $Y 4$ & 68.92 \\
ZK2 & 35.0 & 0 & -240.0 & $Y 4$ & 73.51 \\
ZK3 & 34.0 & -29 & -240.0 & $Y 4$ & 71.29 \\
ZK4 & 43.0 & -64 & -240.0 & $Y 4$ & 74.83 \\
\hline
\end{tabular}

more likely to have a roof and a piece in the excavation process. Therefore, the TRT6000 advanced geological exploration instrument is introduced to the front of the excavation roadway face. The geological conditions are predicted to detect voids or cracks in front of the face, which can effectively prevent and control the stability of the roadway.

2.4.1. TRT6000 Advanced Geological Detection System. The TRT6000 system (Tunnel Reflection Tomography 6000 system) uses a seismic wave advance prediction method, and its basic principles are as follows [23]: when a seismic wave encounters an interface of acoustic impedance difference (density $x$ wave velocity), a part of the excited signal will be reflected and another part of the signal will be sent into the medium in front. When a seismic wave breeds from soft rock to hard rock, the deflection polarity of the reflected wave is the same as the wave source. When there is a rupture zone inside the rock mass, the polarity of the echo will be reversed. The larger the size of the reflector, the greater the difference in acoustic impedance, the more obvious the echo, and the easier the echo is to detect [24]. The TRT6000 system uses tomography imaging technology to form a three-dimensional stereotype. The reflection boundary in the stereogram is spat imposed based on the seismic waveform to form a discrete image (shown in Figure 6).

2.4.2. TRT6000 Advanced Geological Detection System. The exploration test is carried out on the prospecting roadway. The field test is shown in Figure 7 below.

A sensor (1st row and 3rd row) is arranged at the top of the roadway section, one sensor (1st to 4 th row) is arranged in each of the two groups, and 3 5 seismic waves are collected at each source point.

Then, approximately $10 \mathrm{~m}$ from the back of the source point, the sensors are arranged. The distance between each group of sensors is $5 \mathrm{~m}$, for a total of 10 sensors. After all the instruments are connected, tap the source point with a sledgehammer to collect and receive data.
2.4.3. Detection Results and Analysis. According to Figure 8, the three-dimensional image generated by the detection is $140 \mathrm{~m}$ long, $40 \mathrm{~m}$ wide, and $40 \mathrm{~m}$ high and the length of the roadway is $34 \mathrm{~m}$. The analysis results are as follows:

(i) In the range of $0 \sim 15 \mathrm{~m}$ in front of the center point of the face, the reflection energy is weak, and there is almost no reflector. It can be inferred that the integrity of the surrounding rock structure of the roadway in this area is relatively good, but it does not rule out the existence of a small range of joint crack structures.

(ii) In the range of $15 \sim 30 \mathrm{~m}$ in front of the center point of the face, the reflection energy is strong, and the negative reflection is dominant. Combined with the excavation roadway, the position of the ore boundary is measured. The left side of the face is 18.5 meters, the right side is 20.5 meters, and the average 19.5 meters is the interface between the ore body and the surrounding rock. Since the density of the ore body is larger than that of the surrounding rock, the seismic wave enters the low-impedance rock mass from the high-impedance rock mass, where negative reflection should occur, that is, a blue low-impedance anomaly occurs. This is approximately $20 \mathrm{~m}$ in front of the face of the probe. The large-scale blue low-impedance anomalies, which are dominated by negative reflections, coincide with each other. Therefore, it is inferred that this is the interface between the ore body and the surrounding rock.

(iii) In the central line of the roadway within the range of $35 \sim 60 \mathrm{~m}$ in front of the center point of the face, the reflection energy is strong, and the positive and negative reflections alternate. It is speculated that the rock mass in the range is broken.

(iv) In the range of $60 \sim 70 \mathrm{~m}$ in front of the center point of the face, the reflection energy is strong, and the positive reflection is dominant. It is inferred that there may be a rock mass with higher density in this area. 


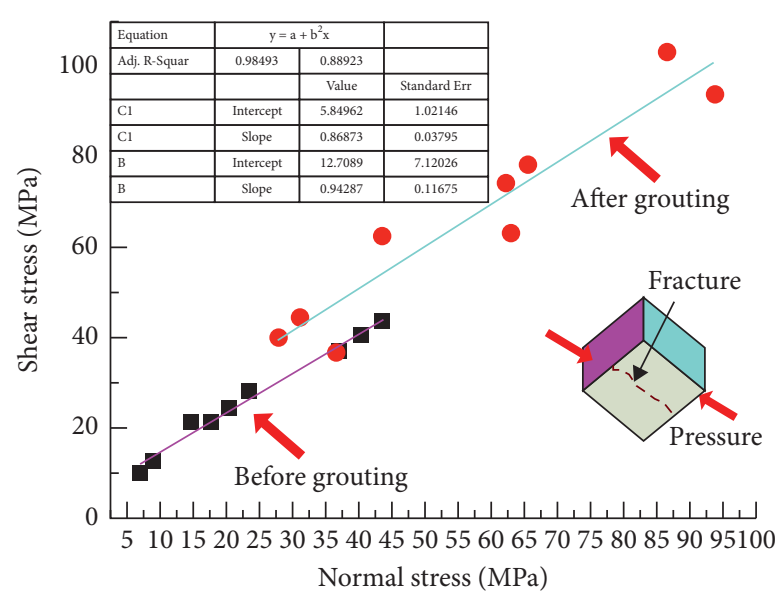

FIGURE 4: Comparison of normal stress-shear stress curves before and after grouting reinforcement of the ore body.

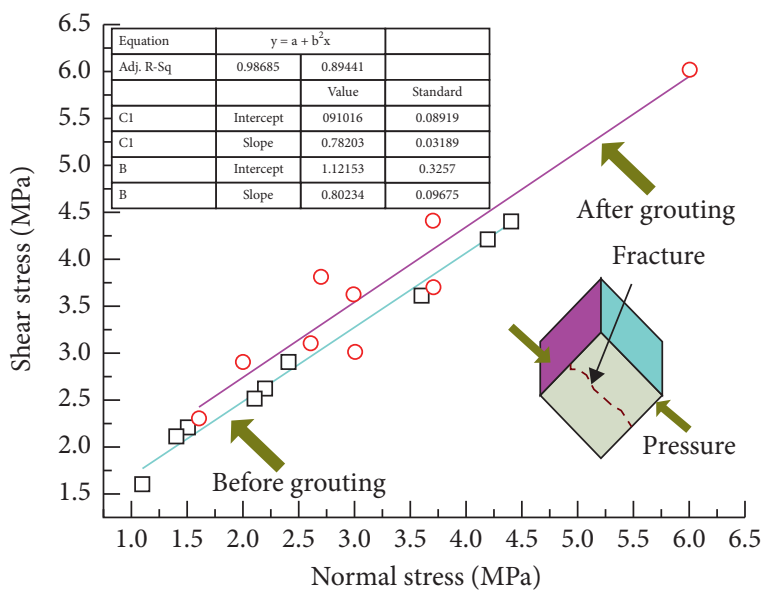

(a)

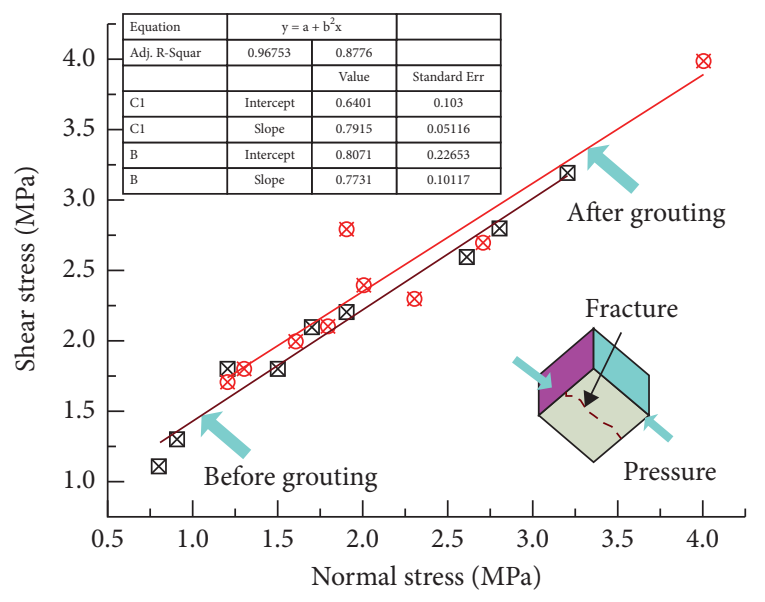

(b)

FIGURE 5: Comparison of normal stress-shear stress curves before and after grouting reinforcement of the filling body.

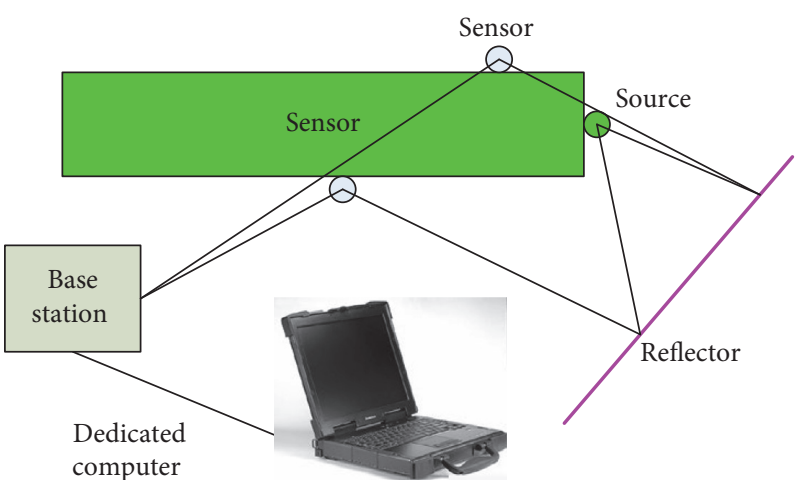

FIgURE 6: Schematic diagram of the detection principle.

(v) In the upper $20 \sim 30 \mathrm{~m}$ range of the roadway, the reflection energy is strong, and the positive and negative reflections alternate. It is speculated that the rock mass in the section is broken. (vi) It can be seen from the front view of the roadway that there is a sporadic weak reflector in the area approximately $15 \mathrm{~m}$ to the left of the centerline of the roadway, which is mainly a positive reflection. It 


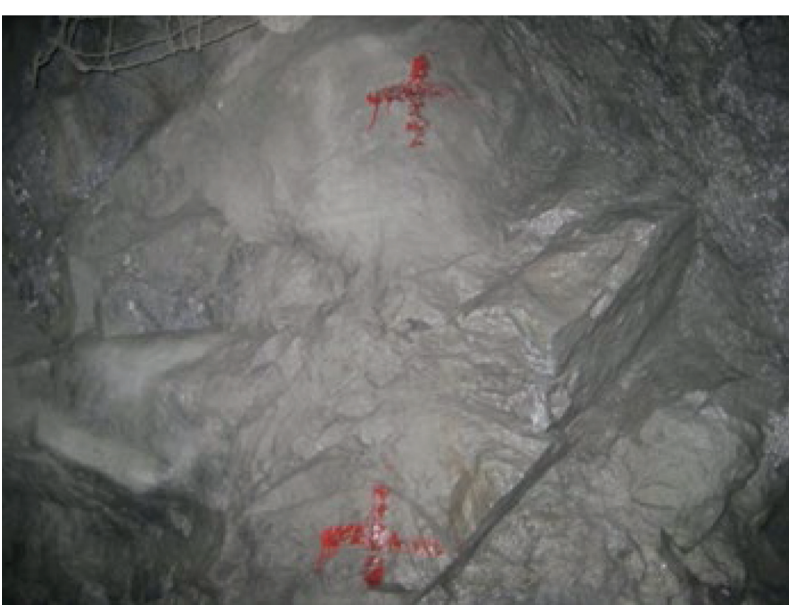

(a)

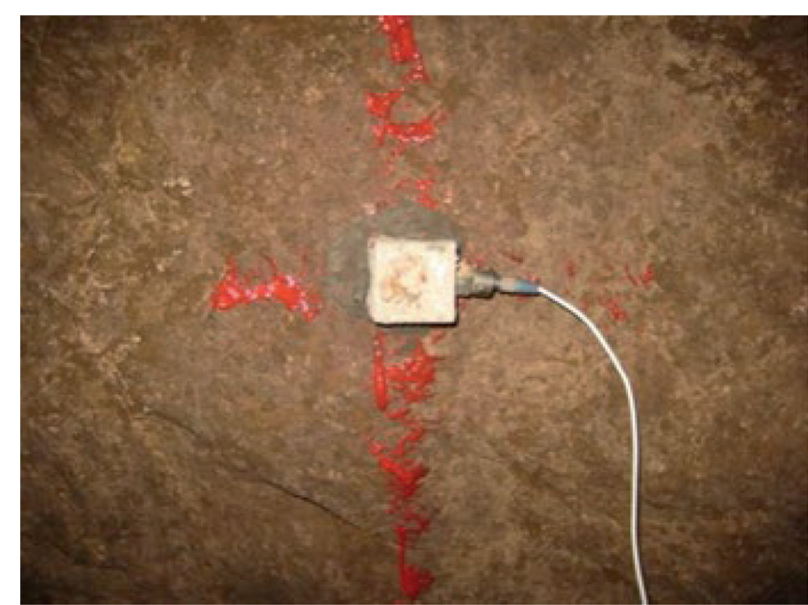

(b)

FIgURE 7: Detection implementation: (a) point marker and (b) sensor and fixed block installation.

is speculated that there are a few joint cracks in the rock mass, probably because of collapse. The resulting broken belt is moved; therefore, later grouting and detection should pay more attention to the stability of the area.

\section{Dynamics Numerical Simulation Analysis}

The dynamic numerical model of the stope is built by using the AUTODYN-3D module set in the finite element software ANSYS12.0. The explosive and stope elements in the model are smoothly meshed SPH particles. The algorithm coupled by FEM and SPH constrains the model boundary, while the SPH particle and LAGRANGE unit directly adopt point-point contact. The absorption boundary constraint is selected on the three sides and bottom of the LAGRANGE unit of the stope. The model pulls down the roadway and cuts. On the side of the patio, you choose the free border. To equate states using the JWL equation of state [25], air uses the ideal gas state equation [26], and the constitutive parameters of rock RHT are determined by the experimental results of the physical and mechanical properties of the ore. According to the method of determining the parameters of the constitutive model of the RHT material, the constitutive parameters of the RHT material of the rock can be obtained [27].

3.1. Calculation Model Establishment. The stope blasting model has been simplified. [28], the length $\times$ width $\times$ height of the model are $34 \mathrm{~m}, 24 \mathrm{~m}$, and $18 \mathrm{~m}$, respectively, the depth of the blast hole is $7.8 \mathrm{~m}$, the diameter of the blast hole is $0.32 \mathrm{~m}$, the cylindrical blast hole is built inside the rock body, and the coupling charge structure is adopted. The vertical distance between the column and the orifice is $1.1 \mathrm{~m}$. The detonation method is reverse detonation. The bottom of the stope and the three sides are built with a $0.2 \mathrm{~m}$ thick LAGRANGE unit. On the blast-hole control boundary, every $1.4 \mathrm{~m}$ along the $X$-axis direction set the gauge recording points ( 5 in total), and the number of holes is 5 rows $\times 5$ columns (see Figure 9 below). Before the simulation, according to field engineering, the blasting detonation sequence that is usually used is now the blasting method adopted for each row of blasting, and the detonation time of the same row is always. Through on-the-spot investigation, this method has produced a large blasting vibration because the front and rear blast holes of the side holes do not produce common squeezing action. To further reduce the blasting vibration, a new blasting detonation method is proposed. The edge of the blast hole is the same as the blasting time of the second row, and so on, by simulating the extrusion blasting effect and the vibration reduction efficiency of the two different initiation sequences to obtain a better initiation sequence. The two different initiation sequences are shown in Figure 10 below.

3.2. Simulation Result Analysis. The model was solved by using AUTODYN-12.0, and the formation process of the cavity and the rock throwing and variation of the free surface were obtained.

The results of the preset Gaussian points are extracted from the software built-in commands to obtain the velocitytime-history plot and the pressure-time-course curve of the rock (see Figures 11 and 12).

3.2.1. Dynamic Evolution Law of Surrounding Rock Blasting Damage. Rock mass damage is the reduction of the effective bearing area of the rock mass and can be expressed by the following formula [29]:

$$
D_{0}=1-\frac{A_{c}}{A_{y}},
$$

where $A_{c}$ is the bearing area and $A_{y}$ is the total area.

However, in practical engineering, since the two values of $A_{c}$ and $A_{y}$ are difficult to measure, at present, two parameters that are more convenient to measure, elastic modulus and acoustic velocity, are usually used to measure rock damage. 


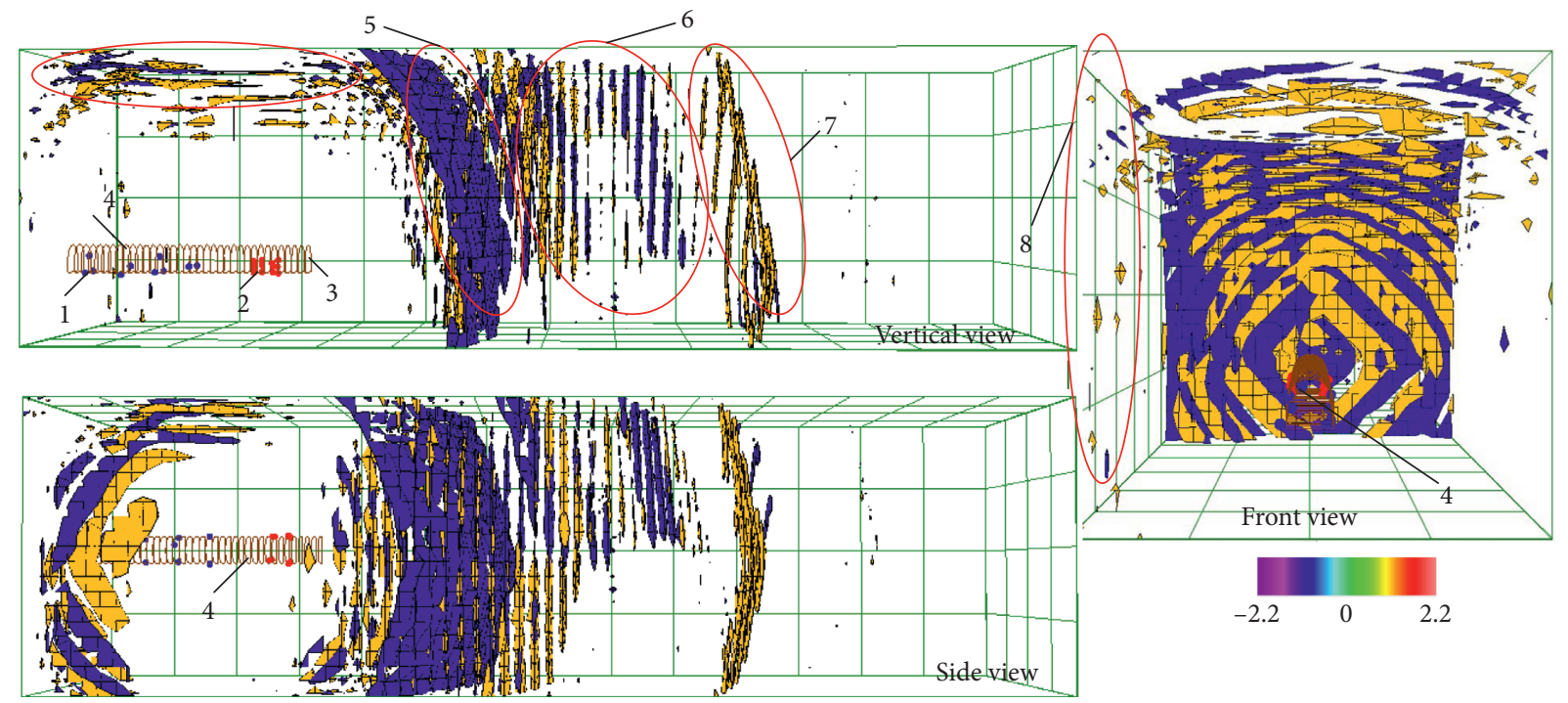

FIgURe 8: Prospecting roadway exploration map.

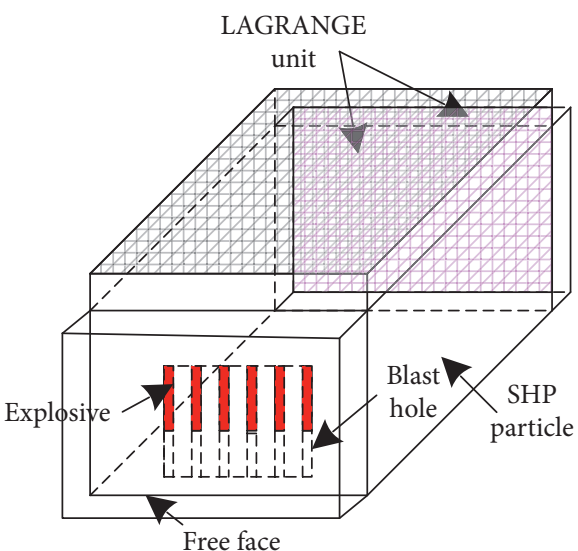

FIGURE 9: Dynamic numerical model of stope.

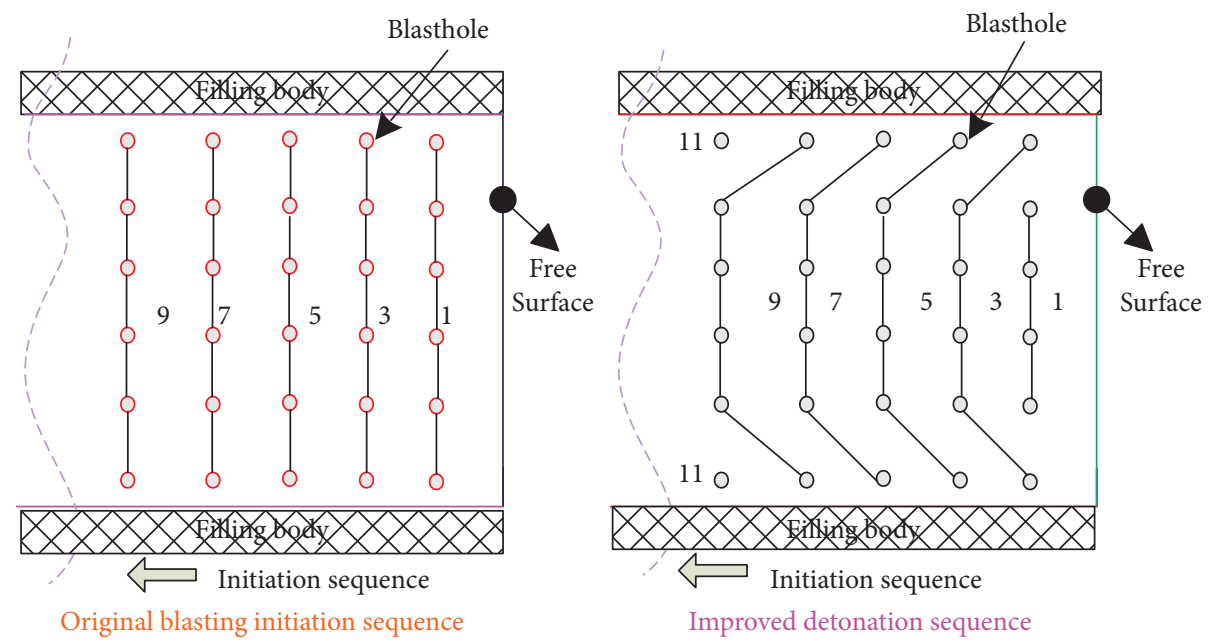

FIgURE 10: Two different blasting initiation sequences. 


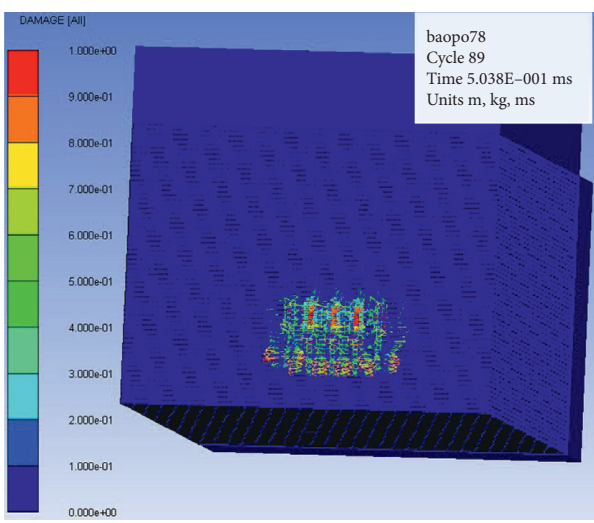

(a)

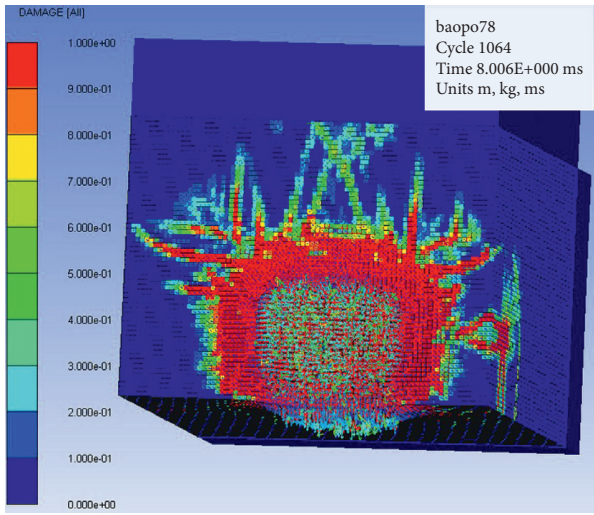

(c)

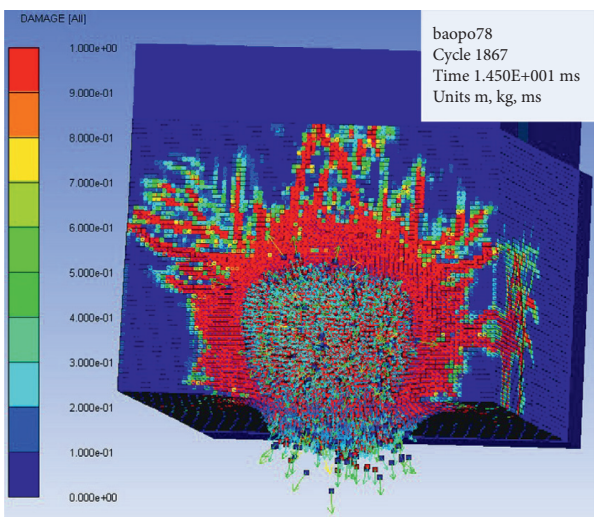

(e)

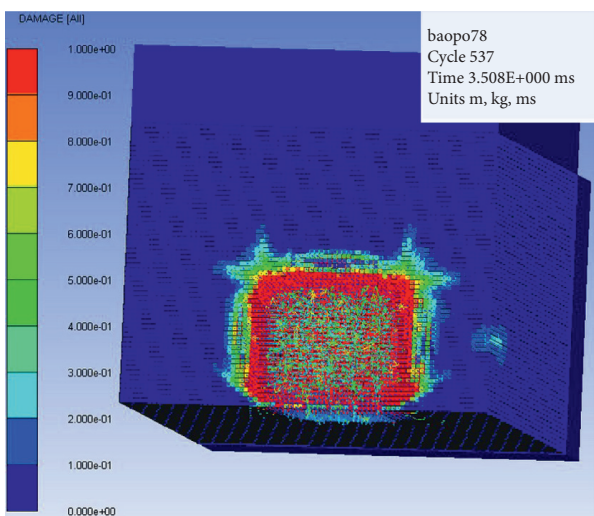

(b)

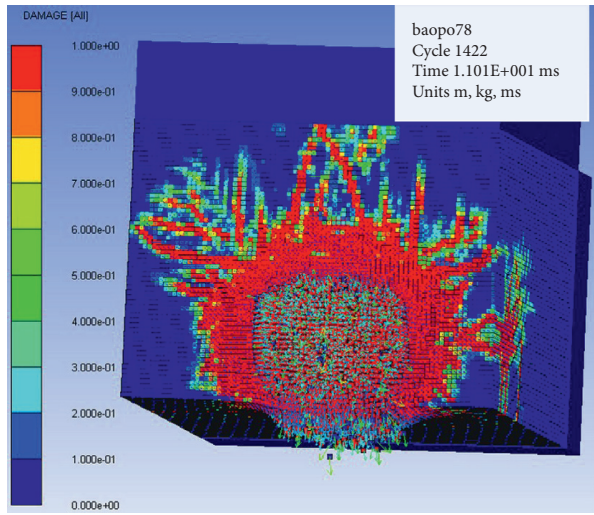

(d)

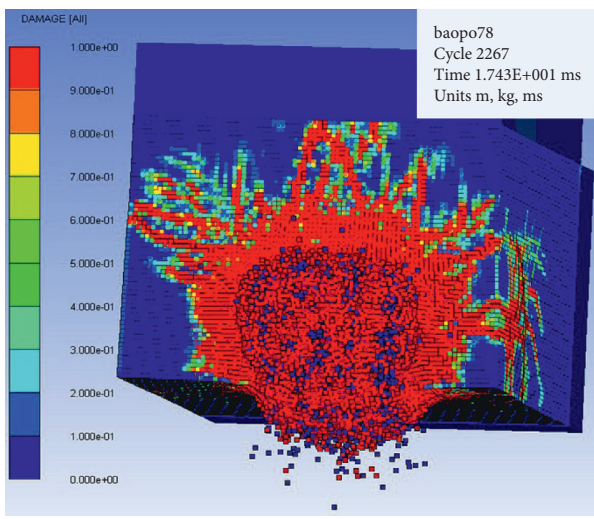

(f)

Figure 11: Damage of the surrounding rock dynamic change rule.

The functional relationship between the rock damage degree $D_{0}$, the integrity coefficient $K$, and the sound velocity reduction rate $\eta$ is as follows:

$$
D_{0}=1-\frac{E_{c}}{E_{y}}=1-\left(\frac{V_{c}}{V_{y}}\right)^{2}=1-K_{0}=1-(1-\eta)^{2},
$$

where $E_{c}$ is the elastic modulus of rock that is not disturbed by the blasting load, $E_{v}$ is the equivalent elastic modulus of the rock after blasting, $V_{c}$ is the acoustic wave velocity of the rock that is not disturbed by the blasting load, and $E_{v}$ is the acoustic wave velocity of the rock after blasting.
The damage in the SHP model is defined as follows: the damage is the accumulation of plastic strain, and the damage variable $D$ can be expressed by the following formula:

$$
D_{0}=\sum \frac{\Delta \varepsilon_{s}+\Delta \mu_{s}}{D_{1}\left(S+T^{N}\right)^{D_{2}}}
$$

where $\Delta \varepsilon_{s}$ is the equivalent plastic strain increment, $\Delta \mu_{s}$ is the equivalent plastic volume strain increment, $T^{N}$ is the dimension normalized pull strength, and $D_{1}$ and $D_{2}$ are the damage parameters. The degree of damage $D_{0}$ increases with the accumulation of plastic strain. After the rock mass 
completely fails, the damage variable $D_{1}=1$; now, the rock mass can only withstand limited pressure and cannot withstand any tensile stress.

Figure 11 shows the damage development process of the surrounding rock under different dynamic loads at different moments. It can be seen from the figure that, after detonation, the high-temperature and high-pressure detonation products generated by the explosives push the surrounding rock mass to expand outward. The shock wave pressure acts directly around the blast hole. The wall of the blast hole in the blasting area first breaks. When the pressure around the wall of the blast hole is greater than the compressive strength of the surrounding rock, the surrounding rock is subjected to compression yielding until crushing by forming a compressed crushing zone.

Over time, the shock wave propagates in the surrounding rock, causing tangential tensile stresses to create radial cracks and expanding toward the periphery. When the shock wave reaches the boundary of the surrounding rock, the wave impedance of the surrounding rock and the surrounding air is different, causing the shock wave to reflect in the surrounding rock by forming a tensile wave and accelerating to destroy the surrounding rock. Because of the vertical deformation of the roof and the tensile stress caused by the lateral deformation of the two surrounding rocks, the part is damaged earlier. Under the dual action of tensile stress and cracks, the first crack formed expands to the periphery, resulting in the surrounding rock being broken and the damage range expanding. After that, the second row of blast holes detonated and interacted with the rock that collapsed in the previous row of blast holes. With the multiple reflections of the explosion shock wave inside the surrounding rock, the cracks expand more and more, and the surrounding rock is destroyed more seriously, and after the explosion wave ends, the interior of the surrounding rock will continue to rise and fall under to act inertia, further increasing The damage of the surrounding rock eventually led to the loss of part of the bearing capacity of the surrounding rock. Until the last row of blasting holes is completed, the resulting damage range is shown in Figure 11(f).

\subsubsection{Numerical Analysis of the Dynamic Evolution Law of} Blasting Acoustic Wave Velocity. The change in acoustic wave velocity of the surrounding rock under blasting loading can also indirectly explain the damage to the surrounding rock. Considering the definition of rock mass damage and the first acoustic wave velocity of the rock mass, under the impact load of the rock, when the sound velocity decrease rate is $10 \%$, the rock mass can be determined to be damaged by blasting damage. Therefore, when the acoustic wave velocity of the surrounding rock is as shown in Figure 12, the damage zone is lowered when it is approximately $4168 \mathrm{~m} / \mathrm{s}$ and the rock can be judged to have damage. According to the dispersal of acoustic wave velocity in the rock mass mainly located in the annular region around the blast hole, the damage zone is larger near the free surface and the rock mass damage near the hole wall is also more serious. As the number of blast holes increases, the damage range continues to expand. The increase in the number of blast holes directly increases the effect of explosive rock breaking.

3.2.3. Vibration Velocity and Pressure-Time Curve Analysis of Surrounding Rock Blasting. The result of extracting the preset Gaussian point from the built-in command of the software can obtain the velocity-time history curve and the pressure-time history curve of the rock block (see Figures 13 and 14). According to the analysis, the horizontal direction of the surrounding rock mass point can be obtained. The peak value of the vibration velocity is approximately $3.51 \mathrm{~cm} / \mathrm{s}$, and the peak value of the monitoring point is approximately 407.1 $\mathrm{MPa}$. The peak value of the monitoring point and the peak value of the vibration velocity in the horizontal direction appear approximately $0.21 \mathrm{~ms}$ after the detonation of the explosive. The larger value fluctuation ends at approximately $0.23 \mathrm{~ms}$, indicating that the formation of the fracture zone is extremely short; it basically ends within $0.25 \mathrm{~ms}$ after the explosion of explosives. Thereafter, with the continuous spread of the explosion shock wave, the pressure of the monitoring point and the vibration velocity of the particle point fluctuate slightly and gradually become stable. At this time, the vibration caused by the explosion shock wave has an almost negligible influence on the surrounding rock.

By comparing the two detonation sequences, the blasting vibration peak and the blasting pressure value are reduced due to the blasting of the two gangs. The blasting vibration peak and the blasting pressure value are reduced, which indicates that the blasting vibration can be reduced to some extent by changing the detonation sequence of the blasting. In turn, it protects the stability of the two surrounding rocks.

The peak value of the monitoring point is approximately 407.1 $\mathrm{MPa}$, the peak velocity of the surrounding rock mass in the horizontal direction is approximately $3.51 \mathrm{~cm} / \mathrm{s}$, and the peak velocity of the surrounding rock mass in the horizontal direction is approximately $1.43 \mathrm{~cm} / \mathrm{s}$. The peak value of the monitoring point and the peak value of the vibration velocity in the horizontal direction appear at approximately $0.21 \mathrm{~ms}$ after detonating the explosive. The larger value fluctuation ends at approximately $0.23 \mathrm{~ms}$, showing that the formation of the crack zone is extremely short. After that, with the continuous spread of the explosion shock wave, the pressure of the monitoring point and the vibration velocity of the particle point rise and fall slightly and gradually become stable. Now, the vibration caused by the explosion shock wave has an almost negligible influence on the surrounding rock.

In summary, the study of the formation process of the entire stop blasting and the rock throwing speed vector analysis of the free surface can lead to the following conclusions:

(i) From the dynamic evolution law of surrounding rock blasting damage, the initiation sequence of the side hole is the primary factor affecting the stability of the surrounding rock. It is feasible to adjust the detonation time of the side hole to a lag for a period 


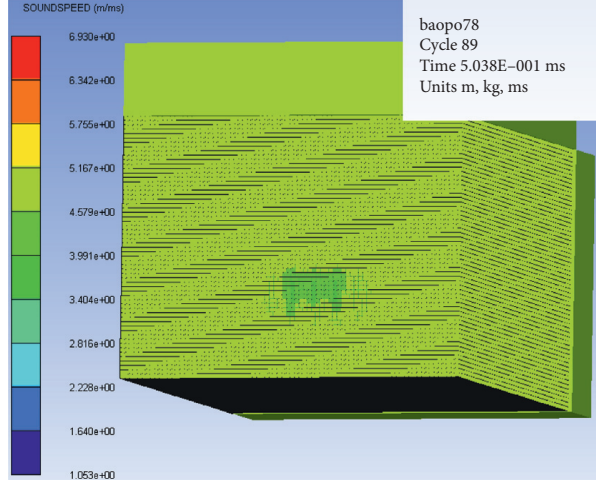

(a)

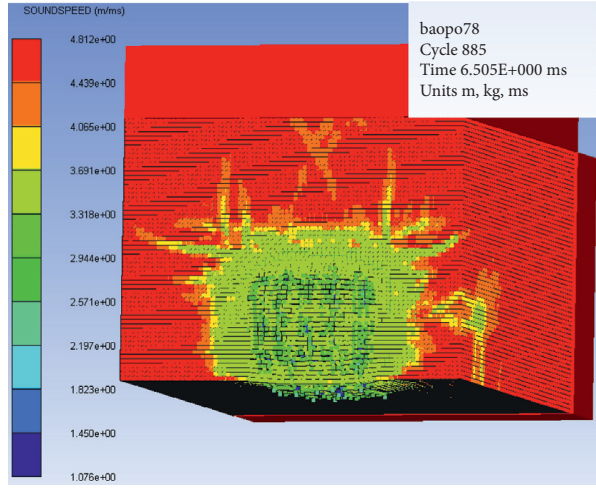

(c)

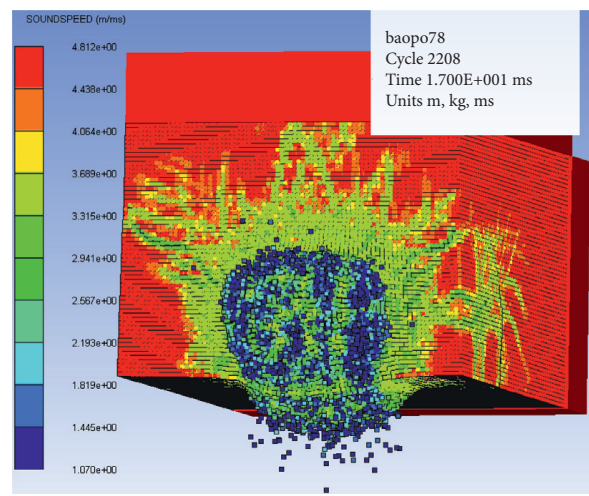

(e)

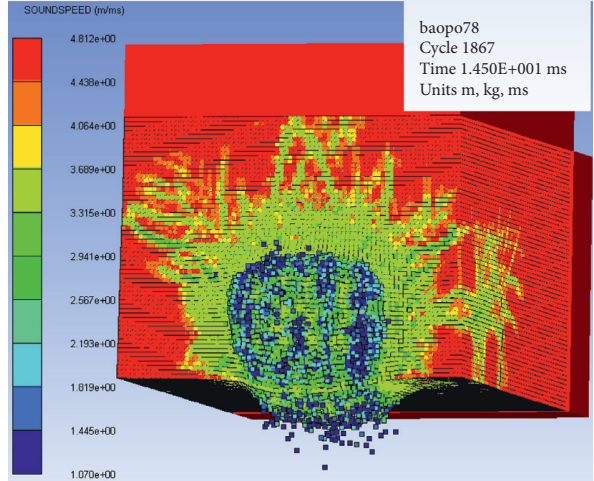

(b)

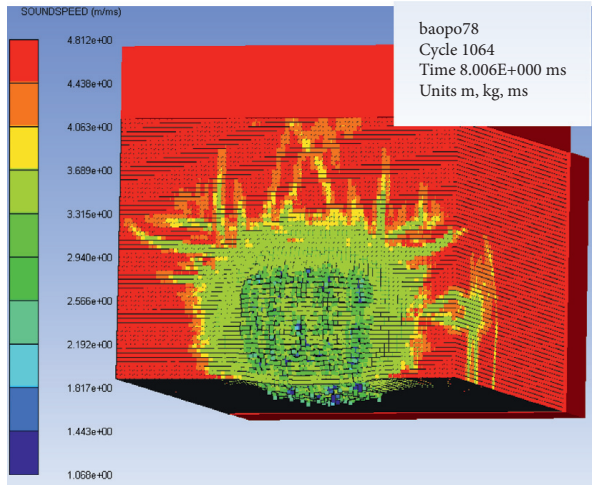

(d)

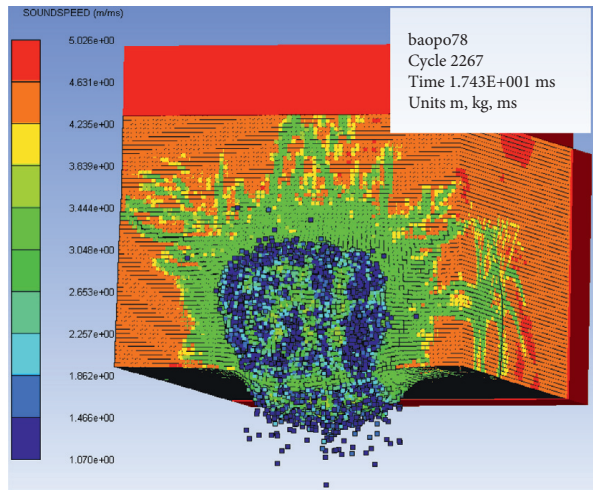

(f)

FIGURE 12: Variation law of sound wave velocity of surrounding rock under blasting load.

of initiation by appropriately adjusting the starting sequence of the edge hole method.

(ii) The numerical analysis results from the dynamic evolution law of blasting sound wave velocity show the edge hole lags for a period of detonation, which indirectly reduces the number of blasting of each row of blast holes, which is obvious for reducing blasting damage.

(iii) From the analysis results of the surrounding rock blasting vibration velocity and pressure-time curve, it can be seen that because of blasting the side hole, the rock breaking after blasting the side hole can play the role of blasting and damping. It can be squeezed with the falling rock generated by the back row detonation, which improves the blasting efficiency.

\section{CMS Field Test Verification}

The effect of using the improved blasting initiation mode can be obtained according to the test at the site. Because of the dark light underground, the image obtained by the camera has a lower resolution and is laser-detected [30]. By producing a three-dimensional visualization model for analysis, the blasting effect can be effectively determined. Using a CMS (cavity monitoring system) instrument [31-34], the detection of the goaf (above Figure 15 is the pattern after introducing Surpac software), compared with the blasting design model, the 

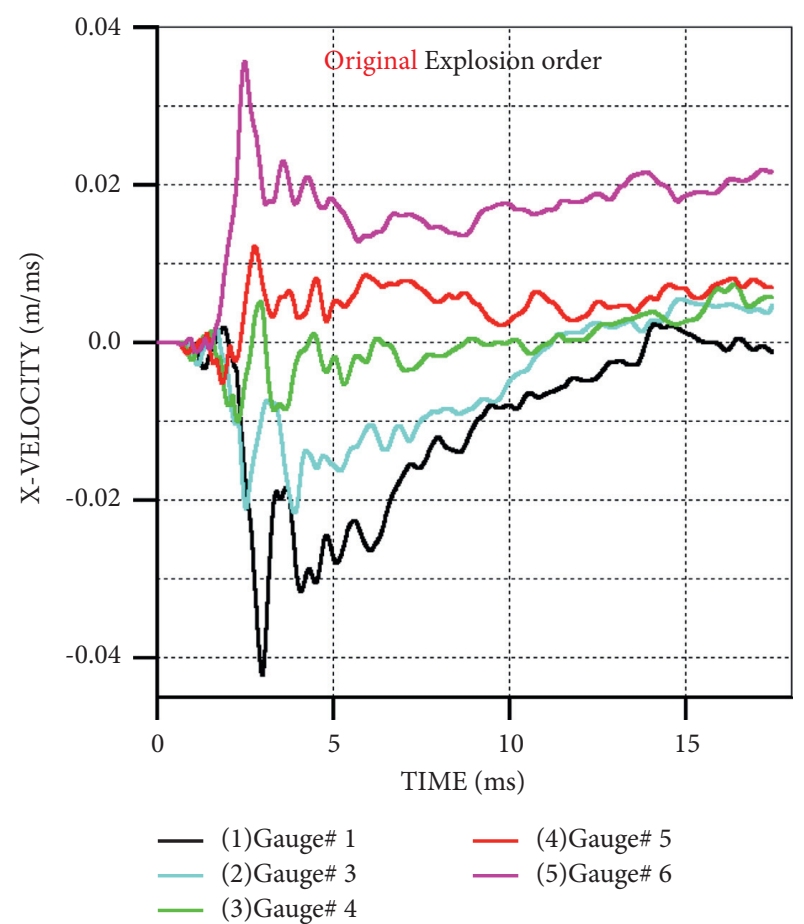

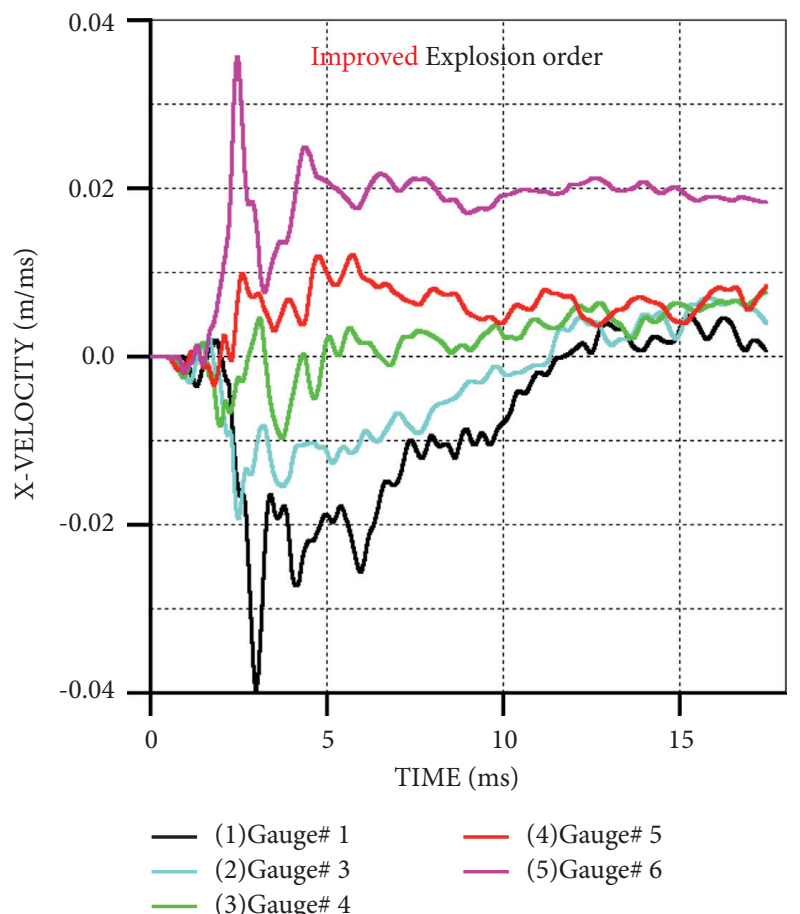

FIGURE 13: Gaussian monitoring time-velocity curve ( $x$ direction).
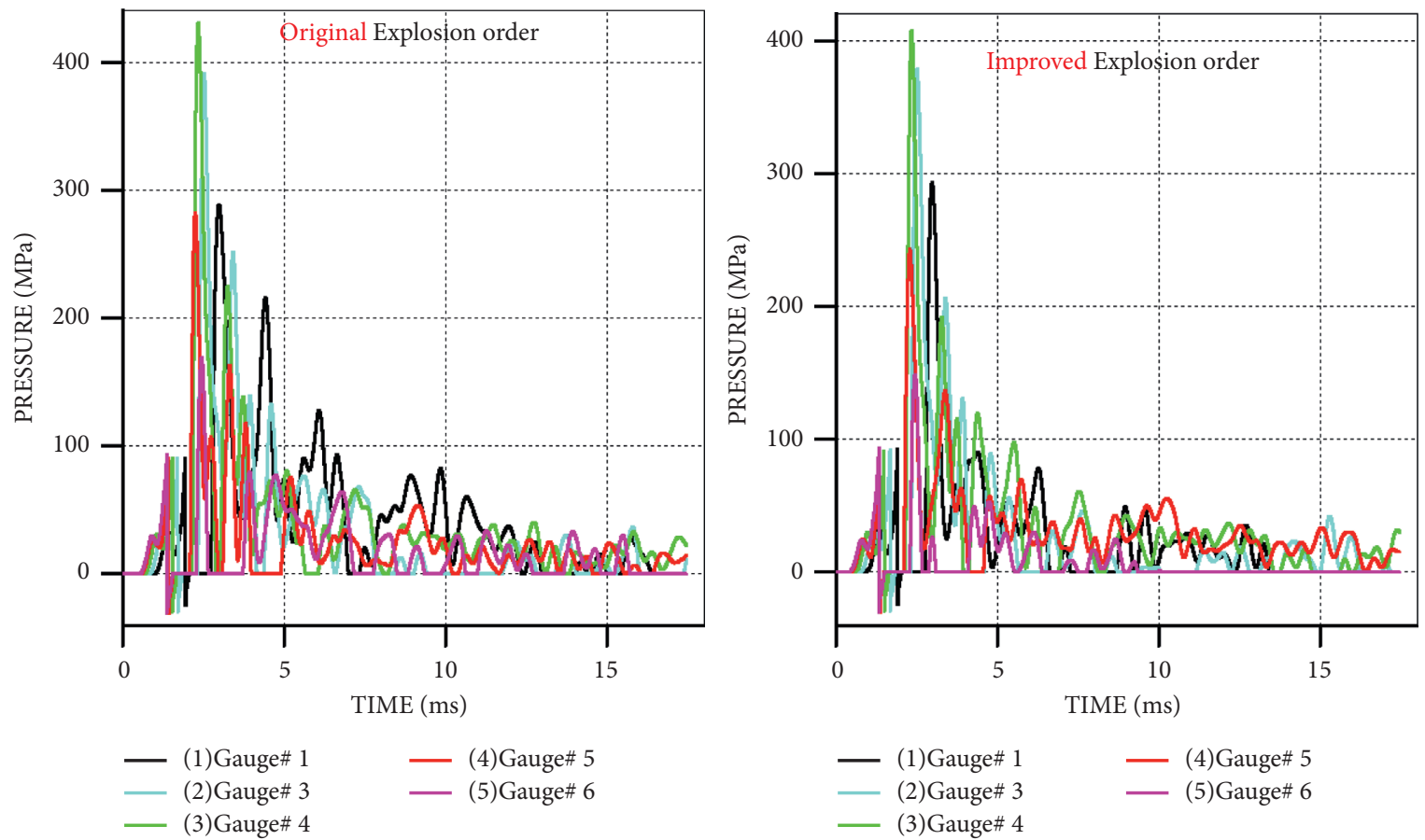

FIGURE 14: Gaussian monitoring time-pressure curve.

protection effect of the two gang fillers is better and the two gangs cannot be observed through the scene. The collapse of the bulk filling body shows that the filling of the two gangs is relatively stable, showing that the optimized blasting parameters can reduce the blasting vibration damage to the two gangs and improve the stability of the two gangs. From the comparison between the implementation and the dashed line in the figure, it can be seen that the numerical simulation results obtained after blasting damping are closer to the results of the three-dimensional visualization model. The optimized 

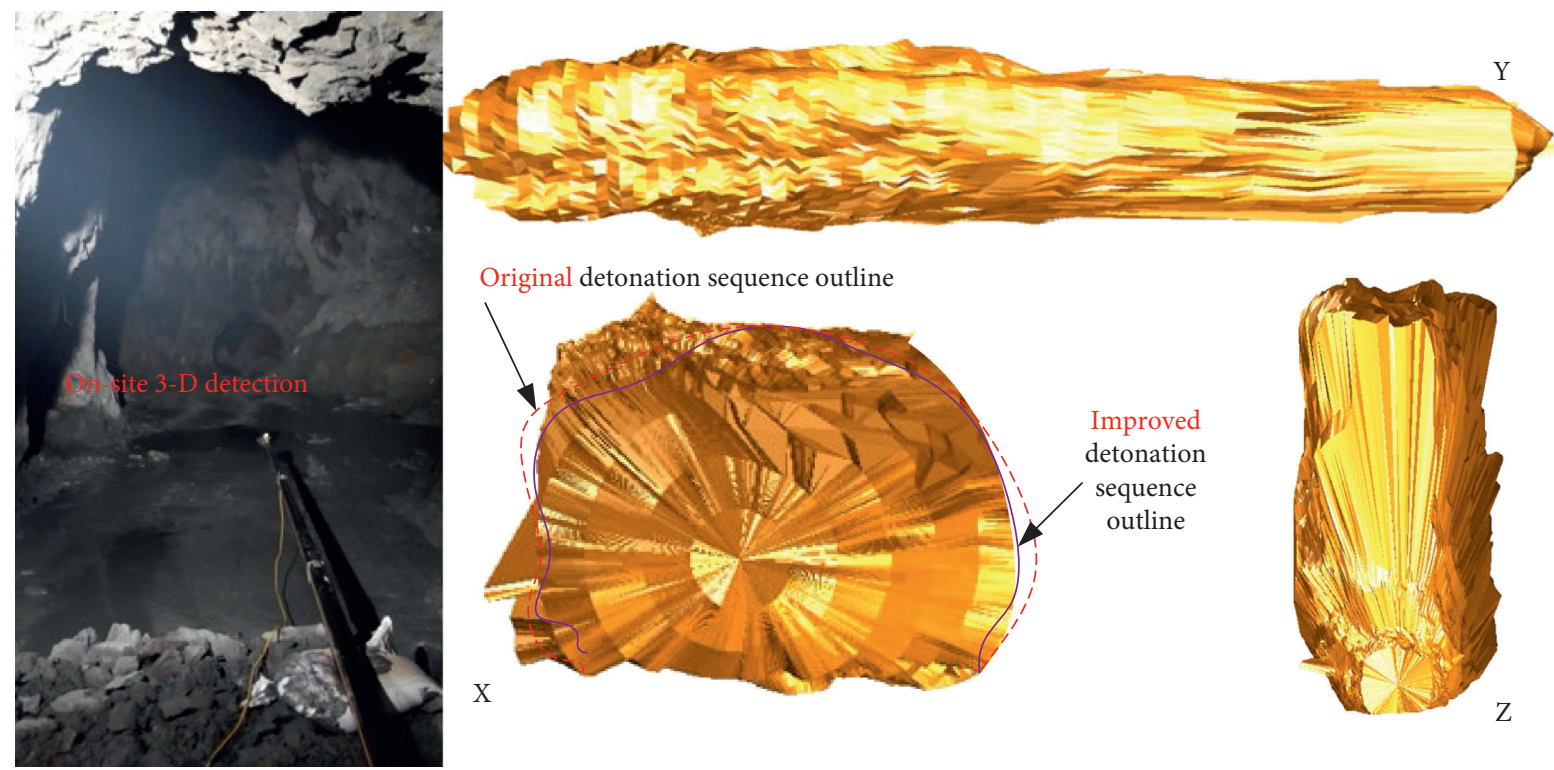

FIGURE 15: Field detection and 3D model.

charging structure has a low bulk rate and good blasting vibration. The control has maximized to protect the fillings of the two gangs in the recovery of hidden danger resources in the mine.

\section{Conclusions}

This paper introduces a case study of the comprehensive method for controlling the stability of surrounding rock in stope mining. A lead-zinc deposit in China has a typical large-scale degraded area because of the collapse of the goaf. Based on information collected and analyzed from the field and laboratory (including rock mechanics experiments, onsite coring analysis, and grouting reinforcement analysis), the TRT6000 advanced geological prediction instrument is used to predict the damage characteristics of complex rock masses in the area. For a complex collapse environment, the detailed dynamics numerical analysis model was determined by using AUTODYNA software. The dynamic failure process of the surrounding rock of the underground chamber was successfully replicated under different detonation sequence schemes. The dynamic changes in surrounding rock damage and crack propagation are analyzed. Based on the on-site monitoring and simulation results, the dynamic damage process of the surrounding rock in the complex collapse area is revealed. Under the dynamic stress caused by the excavation, the damage occurs first around the surrounding rock hole. With the diffusion of explosive waves, this caused damage to the surrounding rock in a certain area. At the same time, because of the large-area tensile failure phenomenon of the surrounding rock, expansion and separation occur around the roadway, and the superposition of the blasting gas and the detonation wave also exacerbates the greater deformation and damage. To improve the blasting effect and reduce the damage of the surrounding rock, a detonation method is proposed in which the front side hole lags behind the rear blast hole. Numerical simulations and field goaf tests were used to compare the control effects of the two detonation sequences on the blasting vibration. The results show that the new detonation sequence can effectively improve the stability of the surrounding rock of the roadway. This case study can provide a reference for exploring the damage process and control technology of surrounding rock in stope mining around abandoned areas.

\section{Data Availability}

The data used to support the findings of the study are included within this article.

\section{Conflicts of Interest}

The authors declare that they have no conflicts of interest.

\section{Acknowledgments}

This research was funded by the Natural Science Foundation of Hunan Province, Grant no. “2021JJ30679,” and Natural Science Foundation of Hunan Province Grant no. “2021JJ40538."

\section{References}

[1] C. Xie, N. Jia, and L. He, "Study on the instability mechanism and grouting reinforcement repair of large-scale underground stopes," Advances in Civil Engineering, vol. 2020, Article ID 8832012, 10 pages, 2020.

[2] F. Wang, B. Jiang, S. Chen, and M. Ren, "Surface collapse control under thick unconsolidated layers by backfilling strip mining in coal mines," International Journal of Rock Mechanics and Mining Sciences, vol. 113, no. 113, pp. 268-277, 2019.

[3] N. L. Fazio, M. Perrotti, P. Lollino et al., "A three-dimensional back-analysis of the collapse of an underground cavity in soft 
rocks," Engineering Geology, vol. 228, no. 228, pp. 301-311, 2017.

[4] L. U. O. Zhou-quan, W. Wang, Q. I. N. Ya-guang, and J. Xiang, "Early warning of rock mass instability based on multi-field coupling analysis and microseismicmonitoring," Transactions of Nonferrous Metals Society of China, vol. 29, no. 6, pp. 1285-1293, 2019.

[5] H. K. Verma, N. K. Samadhiya, M. Singh, R. K. Goel, and P. K. Singh, "Blast induced rock mass damage around tunnels," Tunnelling and Underground Space Technology, vol. 71, no. 72, pp. 149-158, 2018.

[6] L. Jian-po, L. Yuan-hui, and X. Shi-da, "Relationship between microseismic activities and mining parameters during deep mining process," Journal of Applied Geophysics, vol. 159, pp. 814-823, 2018.

[7] K. Xia, C. Chen, Y. Zheng et al., "Engineering geology and ground collapse mechanism in the Chengchao iron-ore mine in China," Engineering Geology, vol. 249, no. 249, pp. 129-147, 2019.

[8] C. He and J. Yang, "Experimental and numerical investigations of dynamic failure process in rock under blast loading," Tunnelling and Underground Space Technology, vol. 83, no. 83, pp. 552-564, 2019.

[9] C. Liu, J. Yang, and B. Yu, "Rock-breaking mechanism and experimental analysis of confined blasting of borehole surroundingrock," International Journal of Mining Science and Technology, vol. 27, no. 5, pp. 795-801, 2017.

[10] H. T. Wang, L. G. Wang, S. C. Li, Q. Wang, P. Liu, and X. J. Li, "Roof collapse mechanisms for a shallow tunnel in two-layer rock strata incorporating the influence of groundwater," Engineering Failure Analysis, vol. 98, no. 98, pp. 215-227, 2019.

[11] Z. C. WeiyiCai, D. Zhang, X. Wang, W. Cao, and Y. Zhou, "Roof filling control technology and application to mine roadway damage in small pit goaf," International Journal of Mining Science and Technology, vol. 29, pp. 477-482, 2019.

[12] B. Ukritchon and S. Keawsawasvong, "Stability of unlined square tunnels in Hoek-Brown rock masses based on lower bound analysis," Computers and Geotechnics, vol. 105, no. 105, pp. 249-264, 2019.

[13] J. H. Yang, C. Yao, Q. H. Jiang, W. B. Lu, and S. H. Jiang, "2D numerical analysis of rock damage induced by dynamic insitu stress redistribution and blast loading in underground blasting excavation," Tunnelling and Underground Space Technology, vol. 70, no. 70, pp. 221-232, 2017.

[14] H. M. An, H. Y. Liu, H. Han, X. Zheng, and X. G. Wang, "Hybrid finite-discrete element modelling of dynamic fracture and resultant fragment casting and muck-piling by rock blast," Computers and Geotechnics, vol. 81, no. 81, pp. 322-345, 2017.

[15] F. Ali and M. Lanari, "DEM-SPH simulation of rock blasting," Computers and Geotechnics, vol. 55, pp. 158-164, 2014.

[16] Y. Ju, Y. Wang, C. Su, D. Zhang, and Z. Ren, "Numerical analysis of the dynamic evolution of mining-induced stresses and fractures in multilayered rock strata using continuumbased discrete element methods," International Journal of Rock Mechanics and Mining Sciences, vol. 113, no. 113, pp. 191-210, 2019.

[17] C. Wu, T. Qin, L. Wang, and Z. Liu, "Research on surrounding rock control technology of dongbaowei deep mining roadway," Advances in Civil Engineering, vol. 2021, Article ID 6660989, 10 pages, 2021.

[18] J. Wei, S. Wang, Z. Zhou, D. Li, and L. Guo, "Numerical study of damage to rock surrounding an underground coal roadway excavation," Advances in Civil Engineering, vol. 2020, Article ID 8863289, 16 pages, 2020.

[19] H. Guo, M. Ji, D. Liu, M. Liu, G. Li, and J. Chen, "Mechanism and control of geological disasters in deep engineering under high temperature, ground stress and water pressure," Advances in Civil Engineering, vol. 2020, Article ID 5604642, 2020.

[20] F. Qi, Z. Ma, D. Yang et al., "Stability control mechanism of high-stress roadway surrounding rock by roof fracturing and rock mass filling," Advances in Civil Engineering, vol. 2021, Article ID 6658317, 17 pages, 2021.

[21] M. Ali and F. TabatabaeiAlavi, "A numerical study of the behavior of fully grouted rockbolts under dynamic loading," Soil Dynamics and Earthquake Engineering, vol. 54, pp. 66-72, 2013.

[22] Q. Wang, Q. Qin, B. Jiang, H. C. Yu, R. Pan, and S. C. Li, "Study and engineering application on the bolt-grouting reinforcement effect in underground engineering with fractured surrounding rock," Tunnelling and Underground Space Technology, vol. 84, no. 84, pp. 237-247, 2019.

[23] Y. Wu, H. Ma, and G. Chen, "Accuracy optimizing of TRT advance forecast in xishimen iron mine," Procedia Engineering, vol. 84, no. 84, pp. 80-86, 2014.

[24] M. Tian, L. Han, Q. Meng, Y. Jin, and L. Meng, "In situ investigation of the excavation-loose zone in surrounding rocks from mining complex coal seams," Journal of Applied Geophysics, vol. 168, no. 168, pp. 90-100, 2019.

[25] S. Koneshwaran, D. P. Thambiratnam, and C. Gallage, "Blast response of segmented bored tunnel using coupled SPH-fe method," Structure, no. 2, pp. 58-71, 2015.

[26] L. Zhou, Z. Zhu, Y. Dong, Y. Fan, Q. Zhou, and S. Deng, "The influence of impacting orientations on the failure modes of cracked tunnel," International Journal of Impact Engineering, vol. 125, no. 125, pp. 134-142, 2019.

[27] X.-w Hong, W.-b Li, W. Cheng, W.-b Li, and H.-y Xu, "Numerical simulation of the blast wave of a multilayer composite charge," Defence Technology, vol. 16, 2019.

[28] A. H. Salum, V. M. S. R. Murthy, "Optimising blast pulls and controlling blast-induced excavation damage zone in tunnelling through varied rock classes," Tunnelling and Underground Space Technology, vol. 85, pp. 268-277, 2019.

[29] Y. Hu, W. Lu, M. Chen, P. Yan, and Y. Zhang, "Numerical simulation of the complete rock blasting response by SPHDAM-FEM approach," Simulation Modelling Practice and Theory, vol. 56, no. 56, pp. 55-68, 2015.

[30] S. Lou, B. Yang, and Z. Luo, "Three-dimensional information acquisition and visualization application in goaf," Procedia Engineering, vol. 84, pp. 860-867, 2014.

[31] V. Kajzar, R. Kukutsch, P. Waclawik, and J. Nemcik, "Innovative approach to monitoring coal pillar deformation and roof movement using 3D laser technology," Procedia Engineering, vol. 191, no. 191, pp. 873-879, 2017.

[32] J. Liu and G. Jiang, "Use of laboratory indentation tests to study the surface crack propagation caused by various indenters," Engineering Fracture Mechanics, vol. 241, Article ID 107421, 2021.

[33] J. Liu, J. Wang, and W. Wan, "Numerical study of crack propagation in an indented rock specimen," Computers and Geotechnics, vol. 96, pp. 1-11, 2018.

[34] F. Wang, C. Zhang, W. Shuaifeng, X. Zhang, and G. Shenghua, "Whole section anchor-grouting reinforcement technology and its application in underground roadways with loose and fractured surroundingrock," Tunnelling and Underground Space Technology, vol. 51, pp. 133-143, 2016. 